4th International Scientific Conference SEC-IASR 2019, Galati, Romania, 7th - 8th June, 2019

\title{
The Suppression Mediate the Relations between Cyberbullying and Depression, Anxiety and Self-esteem
}

\author{
Mioara BOCA-ZAMFIR \\ https://doi.org/10.18662/lumproc/sec-iasr2019/06
}

How to cite: Boca-Zamfir, M. (2020). The Suppression Mediate the Relations between Cyberbullying and Depression, Anxiety and Self-esteem. In S. Marin \& P. Moisescu (vol. eds.), Lumen Proceedings: Vol. 12. 4th International Scientific Conference SEC-IASR 2019 (pp. 50-58). Iasi, Romania: LUMEN Publishing House.

https://doi.org/10.18662/lumproc/sec-iasr2019/06 


\title{
The Suppression Mediate the Relations between Cyberbullying and Depression, Anxiety and Self-esteem
}

\author{
Mioara BOCA-ZAMFIR ${ }^{1}$
}

\begin{abstract}
Using Internet can be fun, attractive and educative for adolescents but can have also negative consequences. One important threat of the internet is cyberbullying which can be defined as an aggressive behaviour carried out using electronic devices. Many studies have previous demonstrated that cyberbullying is associated with many emotional (fear, angry) and psychological (depression, anxiety) problems. Also, research has shown that adolescents who experience cyberbullying have problems in emotion regulation. The aim of this research is to study the mediated role of suppression in relationships of cyberbullying with depression, anxiety and self-esteem. There were 310 adolescents, aged from 13 to 18 years old (145 males, 165 females) from secondary and high schools of Galati area who completed the questionnaires. The results found a partial mediated role of suppression on the relations between cybervictimisation and depression, anxiety and self-esteem. Higher use of suppression mediates the negative effects of cybervictimisation on psychological states of youth. Specifically, cybervictimisation lead to a higher use of suppression and suppression lead to higher depression and anxiety and to lower self-esteem. The findings of this study could be useful for schools and communities in setting plans and strategies to prevention and treatment of consequences of cyberbullying.
\end{abstract}

Keywords: cyberbullying; depression; anxiety; self-esteem; emotion regulation.

\footnotetext{
1 "Dunărea de Jos" University, Teacher Training Department, Galati, Romania, mioaraz@yahoo.com
} 
Mioara BOCA-ZAMFIR | Lumen Proceedings 12 | SEC-IASR 2019

\section{Introduction}

Technology is changing lives and education all over the world. Through the internet the barriers of communication, information and socialisation are removed [10]. Because of the advancement of technology, the traditional bully has a new form now - cyberbullying. Cyberbullying is an intentional aggressive behaviour made through the use of internet and smartphones [1]. According to the previous research, adolescents involved in cyberbullying suffer depression [8], [11], [12], [26], anxiety [3], [16], [18], low self-esteem [16], [18], [20], anger, fear and shame [15]. Also, adolescents from cyberbullying have problems in emotion regulation [22]. In the last years, cyberbullying has become a growing phenomenon that should be explored in order to prevent and reduce its effects.

\section{Problem Statement}

Studies on cyberbullying and depression have shown that there is a correlation between cybervictimisation and cyberbullying [8], [11], [27]. Adolescents with severe depressive symptoms were more predisposed to be involved in cyberbullying comparing with those who have medium or no depressive symptoms [27]. Also is much likely that adolescents who were victims of bullying or cyberbullying to have suicidal thoughts and attempts (the risk is double for victims than for non-victims) [20].

Adolescence is a vulnerable age for emergence of anxiety and social anxiety because of the challenges in the peer relationship and cognitive developments that can amplify the psychological stress. The research consistently reports that those adolescents who experience cybervictimisation also experience higher levels of anxiety [3], [16]. Many studies have focus on social anxiety and cyberbullying and it was found a positive association between these variables [9], [16], [18].

Self-esteem is another psychological characteristic associated with cyberbullying. Self-esteem is important in identity development of adolescents. Patchin \& Hinduja [20] found that adolescents who experienced cyberbullying, both as a victim and an aggressor, had lower self-esteem than adolescents who had little or no experience in cyberbullying. This relationship was investigated in others research with the same results [16], [18].

The existing literature on how adolescents cope with cyberbullying is mostly referring on technological strategies and behavioral coping strategies like seeking help from peers and receiving social support [25]. Emotion 
regulation is the ability to influence when and how we experience and express the emotion [13]. Studies on emotion regulation and cyberbullying have shown that cybervictims have problems in regulate their emotion [22]. Also adolescents who describe themselves as having few abilities in emotion regulation were at higher risk to become aggressors in cyberbullying [4].

As we presented earlier, the psychological and emotional distress experienced by those involved in cyberbullying is clearly documented. This is the reason why we think that emotion regulation can be an impacting factor on reaction of victims and there are a few studies that explored the importance of emotion regulation strategies in the relationship between cyberbullying and psychological consequences.

\section{Aims of the research}

The objective of this study is to test if emotion regulation strategies mediate the relationships between cybervictimisation and depression, anxiety and self-esteem. The first hypothesis is that reappraisal will mediate the relationship between cyberbullying (cyberaggression, cybervictimisation) and depression, anxiety and self-esteem. The second hypothesis is that suppression will mediate the relationship between cyberbullying (cyberaggression, cybervictimisation) and depression, anxiety and selfesteem..

\section{Research Methods}

\section{Participants and procedure}

A sample of 310 adolescents in grades eight to twelve (13-18 years old) from schools and high schools from Galati area, Romania, filled out the questionnaires.

First it was obtained the consent of the schools' directors after a presentation of the objective and the procedure of the research. Parents were notified and they could refuse to allow their child's participation in the study. Data were collected in April 2017. Volunteered adolescents completed the questionnaire booklet. Data were collected anonymously by the school psychologists. Data collection sessions took approximately 40 minutes.

\section{Measures}

The Revised Cyberbullying Inventory for Students[24] has 24 items and two form labeled cyberaggression and cybervictimisation. Participants have to 
indicate, using a 4 point Likert scale from 1 (none) to 4 (more than three times), if the situation presented by the item, characterize their experiences. A total score of $12-48$ is obtained, high scores indicating the frequent behavior of the aggressor or victim

The Beck Depression Inventory [5] has 21 items that measure depression on a scale started from 0 (no symptom) to 3 (more sever symptom). The participant can choose how many items he/she wants in each series. The total can be between 0 and 63

The State-Trait Anxiety Inventory [23] comprises two scales X1 - state anxiety and X2 - trait anxiety. Each item is quoted from 1 (almost never) to 4 (almost always). The total score may be between 20 and 80 . For this study only the trait anxiety scale will be used as a feature

The Self-Esteem Scale [21] has 10 items on a 5 point Likert scale $(1=$ strong agreement, $5=$ strong disagreement). It measures what a person thinks about him/herself. The total scores may range from 10 to 40, with high values indicating a high self-esteem.

The Emotion Regulation Questionnaire [14] measure two strategies of emotion regulation: expressive suppression (4 items) and cognitive reappraisal (6 items). The participants can choose for an item a response starting from $1=$ "strongly disagree" to 7 = "strongly agree".

\section{Analysis}

In order to test the mediation effect of suppression, the SPSS macro PROCESS (model 4) was applied. Others statistical analyses were made with IBM SPSS Statistics 19.5.

\section{Findings}

For a mediated effect to be tested it is important that the mediators to be significantly correlated with both the predictors and outcome variables

\subsection{Descriptive statistics and bivatiate relations}

Table 1 lists the mean values, standard deviations and the Pearson correlations for the variables of mediation analyses. Reappraisal has a positive. 
Mioara BOCA-ZAMFIR | Lumen Proceedings 12 | SEC-IASR 2019

Table 1. Descriptive statistics and Pearson correlations

$N=310 ; *, p<.05 ;{ }^{* *}, p<.01 ; * * *, p<.001$

\begin{tabular}{lccccccc}
\hline & Mean & SD & 1 & 2 & 3 & 4 & 5 \\
\hline Suppression & 16.39 & 5.25 & .08 & $.13^{*}$ & $.19^{*}$ & $.19^{*}$ & $-.23^{* *}$ \\
Reappraisal & 28.41 & 6.97 & -.08 & .02 & $-.27^{* *}$ & $-.28^{* *}$ & $.30^{* *}$ \\
\hline
\end{tabular}

Note: Cyberaggression $=1$; Cybervictimisation $=2$; Depression $=3$; Anxiety $=4$; Self-esteem $=5$.

No correlation with self-esteem and a negative correlation with depression and no significant correlations with cyberaggression or cybervictimization. Suppression has a significant positive correlation with cybervictimisation, depression and anxiety and a negative association with self-esteem.

\subsection{Results}

The results showed that cybervictimisation is a significant predictor of suppression $(\mathrm{b}=.10, \mathrm{SE}=.04, \mathrm{p}<.05)$ and that suppression is a significant predictor of depression $(\mathrm{b}=.26, \mathrm{SE}=.08, \mathrm{p}<.01)$. Cybervictimisation is a significant predictor of depression $(\mathrm{b}=.27, \mathrm{SE}=.07$, $\mathrm{p}<.01)$ consistent with partial mediation. The indirect coefficient was significant $(\mathrm{b}=.02, \mathrm{SE}=.01,95 \% \mathrm{CI}=.004, .068)$. Approximately $10 \%$ of the variance in depression is explained by the effect of cybervictimisation mediated through suppression $(\mathrm{PM}=.09)$. Being a cybervictim is associated with higher use of suppression which will lead to an increase of depression scores.

Results indicated that cybervictimisation is a significant predictor of suppression $(\mathrm{b}=.10, \mathrm{SE}=.04, \mathrm{p}<.05)$ and that suppression is a significant predictor of anxiety $(\mathrm{b}=.31, \mathrm{SE}=.10, \mathrm{p}<.001)$. Cybervictimisation is a significant predictor of anxiety $(\mathrm{b}=.54, \mathrm{SE}=.09, \mathrm{p}<.001)$, and this is the conditions for a partial mediation. The indirect coefficient is significant $(\mathrm{b}=$ $.03, \mathrm{SE}=.02,95 \% \mathrm{CI}=.004, .086)$. Approximately $6 \%$ of the variance in anxiety is explained by the effect of cybervictimisation mediated through suppression $(\mathrm{PM}=.06)$. Adolescents who are victims of cyberbullying will use suppression which will determine a higher anxiety.

From the results derive that suppression is a predictor of selfesteem ( $\mathrm{b}=-.30, \mathrm{SE}=.08, \mathrm{p}<.001)$ and that cybervictimisation is a significant predictor of self-esteem $(b=-.24, \mathrm{SE}=.06 \mathrm{p}<.001)$. These results support a partial mediational hypothesis. Approximately $12 \%$ of the variance in self-esteem was predicted by cybervictimisation and suppression 
$(\mathrm{PM}=.12)$. The indirect effect was significant $(\mathrm{b}=-.03, \mathrm{SE}=.01,95 \% \mathrm{CI}$ $=-.085,-.006)$. Cybervictims with higher scores at suppression will have lower self-esteem.

\section{Discussions}

To our knowledge, there was no previous research that tested the theoretically suggested mediating role of emotion regulation strategies in the relationships between cyberaggression or cybervictimisation and depression, anxiety and self-esteem. First, we tested the associations between cyberbullying, depression, anxiety, self-esteem and emotion regulation strategies. We confirm the result of others previous studies which obtained a positive correlation between suppression, depression and anxiety and a negative correlation between suppression and self-esteem [6],[7]. Adolescents who have higher scores on depression and anxiety and lower scores on self-esteem, are those who use suppression more. As previous findings suggested, response focused emotion regulation strategies are less efficient in reducing emotion [14]; the use of suppression does not downregulate negative emotions [17] and exaggerated use of suppression is a sign of some psychological disorders, like depression and anxiety [2]. Adolescents with lower scores on depression and anxiety and with higher self-esteem are using more reappraisal. As previously stated before, people who use cognitive reappraisal have less negative emotions and more positive emotion [13] and present less psychopathological symptoms [2].

Secondly, we tested the mediation effect of suppression on relationships between cybervictimisation and depression, anxiety and selfesteem. We obtained significant results for the partial mediation of suppression on effect of cybervictimisation to depression, suggesting that cybervictims tend to use more suppression like an emotion regulation strategies and this will lead to more depressive symptoms. As previously stated, suppression can be an inefficient emotion regulation strategy to use for down regulate the negative emotions. People who use suppression, also use rumination and they experience less social support. All these aspects will increase risk for depressive symptoms [14]. So, adolescents who use expressive suppression in dealing with negative emotions generated by being a victim of cyberbullying can experience an increase in depressive symptoms. Also, cybervictims will use suppression and will have a higher level of anxiety. Previous studies showed that suppression is associated with anxiety [2]. Furthermore, people who commonly use suppression have lower levels of social support, lower relationship satisfaction and more avoidance [14] 
and all these can influence the anxiety's level of cybervictims. These results are contradictory to some others research who didn't found any significant effect of suppression on relationships between cybervictimisation and psychological problems like depression and anxiety [19], [25].Moreover, we have a partial mediated effect of suppression on the relationships between cybervictimisation and self-esteem. In others words, cybervictims who will use suppression will have lower levels of self-esteem. As previous findings suggested, those who suppress their emotions also have less life satisfaction, less optimistic attitude about the future and lower self-esteem [14]. So, suppression has an important mediated role in influence of cybervictimisation on depression, anxiety and self-esteem.

The results of the present study should be with caution take into consideration, because of the inherent limitations. The results are only representative for adolescents between 13 and 18 years old and from a limited geographic region, future research could aim to investigate a more targeted sample. Utilizing self-report measures can be a problem because, due to social desirability, participants may not be willing to reveal a negative situation such as victimization or bullying. On the other hand, with other methods is hard to obtain information about delicate issues like cybervictimisation or cyberaggression or about intrinsic mechanism like emotion regulation. Future research can try to collect data from various sources like peers, friends, teachers or parents.

\section{Conclusions}

The hypotheses were partial validated. The results from this study underscore the importance that emotion regulation strategies (suppression) may play in the relationships between cybervictimisation and depression, anxiety and self-esteem. This could provide an empirical basis for the development of the prevention and intervention programs and for exploration of their effectiveness.

\section{References}

[1] AkȘ Ozdemir Y, Kuzucu Y. Cyber victimization and cyberbullying: the mediating role of anger, don t anger me! Jchb. 2015; 49:437-43.

[2] Aldao A, Nolen-Hoeksema S, Schweizer S. Emotion-regulation strategies across psychopathology: A meta-analytic review. Jcpr. 2010; 30:217-37. doi:10.1016/j.cpr.2009.11.004. 
[3] Aoyama I, Saxon TF, Fearon DD. Internalizing problems among cyberbullying victims and moderator effects of friendship quality. Multicultural Education \& Technology Journal. 2011; 5(2):92-105.

[4] Baroncelli A, Ciucci E. Unique effects of different components of trait emotional intelligence in traditional bullying and cyberbullying. Journal of Adolescence. 2014; 37(6):807-15.

[5] Beck A, Steer R. Internal consistencies of the original and revised Beck Depression Inventory. Journal of Clinical Psychology 1984; 40:1365-67.

[6] Berking M, Whitley B. Emotion Regulation: Definition and Relevance for Mental Health. In Berking M, Whitley B.Affect Regulation Training: A Practitioners' Manual. New York: Springer Science+Business Media; 2014: 517. DOI 10.1007/978-1-4939-1022-9_2.

[7] Borton J, Markowitz L, Dieterich J. Effects of Suppressing Negative SelfReferent Thoughts on Mood and Self-Esteem. Journal of Social and Clinical Psychology. 2005; 24(2):172-90. Available from: https://doi.org/10.1521/ jscp.24.2.172.62269.

[8] Chang FC, Chiu CH, Miao NF, Chen PH, Lee CM, Chiang JT, et al. The relationship between parental mediation and Internet addiction among adolescents, and the association with cyberbullying and depression. Compr Psychiatry. 2015;57:21-28.

[9] Dempsey A, Sulkowski M, Nichols R, Storch E. Differences between peer victimization in cyber and physical settings and associated psychosocial adjustment in early adolescence. Psychol Sch. 2009; 46: 962-72.

[10] Diamanduros T, Downs E, Jenkins SJ. The role of school psychologists in the assessment, prevention, and intervention of cyberbullying. Psychology in the Schools. 2008 Sept; 45(8):692-704.

[11] Erdur-Baker O, Tanrikulu I. Psychological consequences of cyber bullying experiences among Turkish secondary school children. Procedia-Social and Behavioral Sciences. 2010; 2:2771-76.

[12] Gamez-Guadix M., Orue I, Smith PK, Calvete E. Longitudinal and Reciprocal Relations of Cyberbullying with Depression, Substance Use and Problematic Internet Use among Adolescents. J Adolesc Health. 2013; 53:446-52.

[13] Gross J. Emotion Regulation. In Haviland-Jones JM, Barrett LF editors.Handbook of Emotions. New York: The Guilford Press.; 2008; 497-12.

[14] Gross JJ, John O. Individual differences in two emotion regulation processes: implications for affect, relationships, and well-being. Journal of Personality and Social Psychology. 2003; 85(2):348-62.

[15] Hinduja S, Patchin J. Offline consequences of online victimization: School violence and delinquency. Journal of School Violence. 2007; 6(3):89-112.

[16] Juvonen J, Gross E. Extending the school grounds? Bullying experiences in cyberspace. J Sch Health. 2008;78(9):496-05.

[17] Kalokerinos EK, Greenaway KH, Casey JP. Context shapes social judgments of positive emotion suppression and expression. Emo.2017 Feb; 17(1):169-86. doi:10.1037/emo0000222. 
[18] Kowalski RM, Limber SP, Agatston P. Current Research on Cyberbullying. In Kowalski R, Limber S, Agatston P.Cyberbullying: Bullying in the Digital Age. $2^{\text {nd }}$ ed. UK: Blackwell Publishing Ltd; 2012. p. 89-118.

[19] Larsen JK, Vermulst AA, Eisinga R, English T, Gross JJ, Hofman E, et al. Social coping by masking? Parental support and peer victimization as mediators of the relationship between depressive symptoms and expressive suppression in adolescents. J Youth Adolesc. 2012; 41:1628-42. doi: 10.1007/s10964-0129782-7.

[20] Patchin J, Hinduja S. Cyberbullying and Self-Esteem. Journal of School Health. 2010; 80 (12):614-21.

[21] Rosenberg M. Society and the adolescent self-image. New York: Princeton University Press. 1965.

[22] Spence S, De Young A, Toon C, Bond S. A longitudinal examination of the associations between emotional dysregulation, coping responses to peer provocation, and victimization in children. Australian Journal of Psychology 2009; 61(3):145-55.

[23] Spielberger C, Gorsuch R, Lushene R, Vagg P, Jacobs G. Manual for the StateTrait Anxiety Inventory. Palo Alto: CA: Consulting Psychologists Press. 1983

[24] Tanrikulu I. The relationships between cyber bullying perpetration motives and personalty traits: Testıng uses and gratuficatıons theory (Unpublished doctoral thesis). Middle East Technical University, Ankara, Turkey. 2015. Available from:http:/ / etd.lib.metu.edu.tr/upload/12618900/index.pdf.

[25] Topcu C. Modeling the relationships among coping strategies, emotion regulation, rumination, and perceived social suport in victims of cyber and traditional bullying - doctoral thesis; 2014. Available from: http:/ / etd.lib.metu.edu.tr/upload/12618232/index.pdf.

[26] Wang J, Nansel T, Iannotti R. Cyber Bullying and Traditional Bullying: Differential Association with Depression. J Adolesc Health. 2011; 48(4):415-17.

[27] Ybarra M, Mitchell K. Online aggressor/targets, aggressors, and targets: a comparison of associated youth characteristics. Journal of Child Psychology and Psychiatry. 2004; 45(7):1308-16. 